\title{
A case report of COVID-19 evoked cholangitic liver abscess
}

\author{
Omkolsoum Alhaddad', Maha Elsabaawy ${ }^{1 *} \mathbb{D}$, Ahmed Edrees$^{1}$, Essam Elshimy $^{1}$, Dalia Elsabaawy ${ }^{2}$ and \\ Tarek Mansour ${ }^{3}$
}

\begin{abstract}
Background: Lately, the humanity has been being threatened by the coronavirus disease (COVID-19). The virusrelated destructive motives can damage not only the lungs but also the brain, blood vessels, kidneys, and the heart.

Case presentation: A middle-aged female presented with jaundice post-COVID-19 pneumonia. The patient had past history of cholecystectomy 20 years ago. Both laboratory and imaging data revealed a picture of cholestasis with right lobe liver abscess. Despite drainage and culture-based antibiotics, no improvement ensued. Endoscopic retrograde cholangiopancreatography was done revealing mildly dilated common bile duct (CBD), multiple large stones, mildly dilated central biliary radicals, and an old overlooked stent inside the dilated CBD. Papillotomy and papilloplasty were undertaken followed by stones' extraction with insertion of 2 plastic stents $(10 \mathrm{~cm} \times 10 \mathrm{f})$, and a flow of thick dark bile was inspected. The patient was finally improved and safely discharged.
\end{abstract}

Conclusion: Herein, we present the first case of long-retained quiescent biliary stent which was over-headed by a cholangitic abscess in the vicinity of COVID pneumonia.

Keywords: COVID-19, Cholangitic, Choledocholithiasis, Stent

\section{Background}

The emerging COVID-19 disease has been considered this century's lethal curse [1]. Since the first strenuous apprehension from the Chinese city Wuhan, lots of data has been evolving concerning the novel coronavirus [1]. However, the full-blown clinical scenarios, outcomes, and sequelae have not yet unveiled.

COVID 19-related reports have described a postrecovery state of immunosuppression that would boost serious bacterial and fungal infections $[2,3]$.

As more than $60 \%$ of liver abscesses are of biliary origin, so stones, stents, and biliary anomalies are considered the most conventional predispositions of developing pyogenic liver abscesses [4].

\footnotetext{
*Correspondence: maha.ahmed@liver.menofia.edu.eg

${ }^{1}$ Department Of Hepatology and Gastroenterology, National Liver

Institute, Menoufia University, Shebeen El-Kom 32511, Egypt

Full list of author information is available at the end of the article
}

\section{Case presentation}

A 62-year-old lady recently presented to the emergency room of National Liver Institute, Menoufia University, with 3-day history of high fever $\left(41{ }^{\circ} \mathrm{C}\right)$, chills, but neither respiratory symptoms nor alteration of mental status were present. Clinical examination revealed scleral icterus and significant tenderness over the right hypochondrium.

Her history was significant for COVID-19 pneumonia and ICU admission for around 22 days in a nearby hospital 1 month earlier. The patient's past history was not significant apart from an open cholecystectomy 20 years ago with uneventful postoperative period. The patient is neither diabetic nor hypertensive, and no history of past endoscopic procedures.

Laboratory investigations on presentation showed hyperbilirubinemia, leukocytosis, and pattern of cholestatic hepatitis, but normal COVID-19-related laboratory markers. 
Also, immediate point of care ultrasound (POCUS) revealed a right hepatic lobe focal lesion measuring $(10 \times 10 \mathrm{~cm})$, along with an evident stent inside the common bile duct (CBD) (Fig. 1). A consecutive computerized tomography scan of the abdomen confirmed the

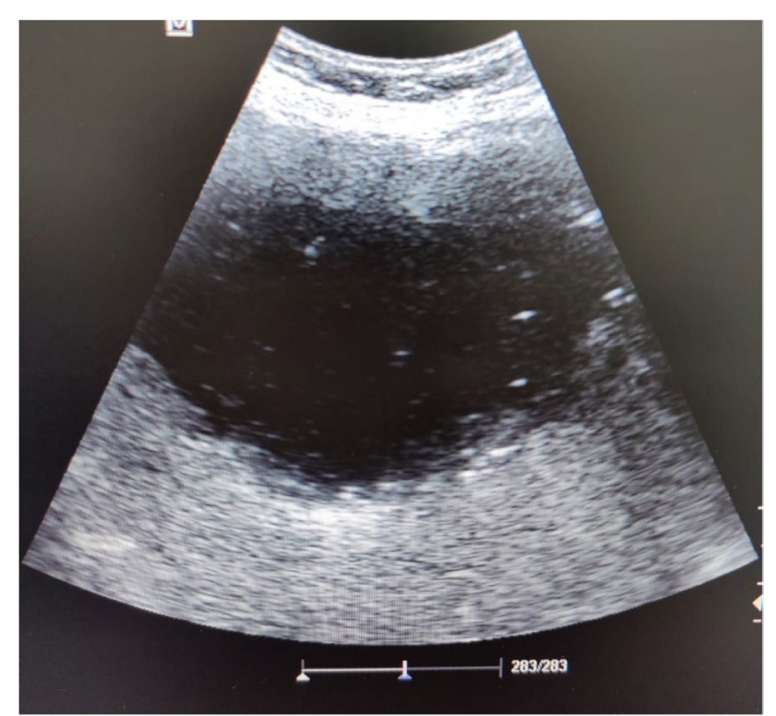

Fig. 1 Ultrasonographic picture of the right liver lobe delineating cystic like structure with fine reticulations right lobe focal lesion as a complex abscess occupying large area (Figs. 2 and 3).

Sonography guided, a 10 -french pigtail catheter was inserted percutaneously into the abscess cavity meanwhile, with aspiration of $50 \mathrm{~mL}$ of purulent fluid that was sent for culture and sensitivity. The patient was transferred to the ward and parenteral broad-spectrum antibiotics were initiated. Few days later, the culture and sensitivity results gave priority to Escherichia coli, infection with modulation of prescribed antibiotic.

In the following days, the clinical status of the patient did not show any improvement with persistent fever, discharge from the pigtail, and non-change in sonographic measures of the abscess cavity. The antibiotic regimen was changed according to the results of culture and sensitivity from the pigtail discharge.

Further assessment in the following days has confirmed the condition as non-resolving abscess. This nonresponse to the classic measures of abscess treatment (culture-based antibiotics and percutaneous drainage) added to the sonographic findings and the cholestatic liver derangement had mandated stepping to endoscopic retrograde cholangiography (ERCP).

The CBD was cannulated after strenuous extraction of a long $(20 \mathrm{~cm})$ catheter that was largely displaced into the duodenal lumen. Cholangiogram revealed mildly dilated CBD with multiple large stones accompanied by mildly

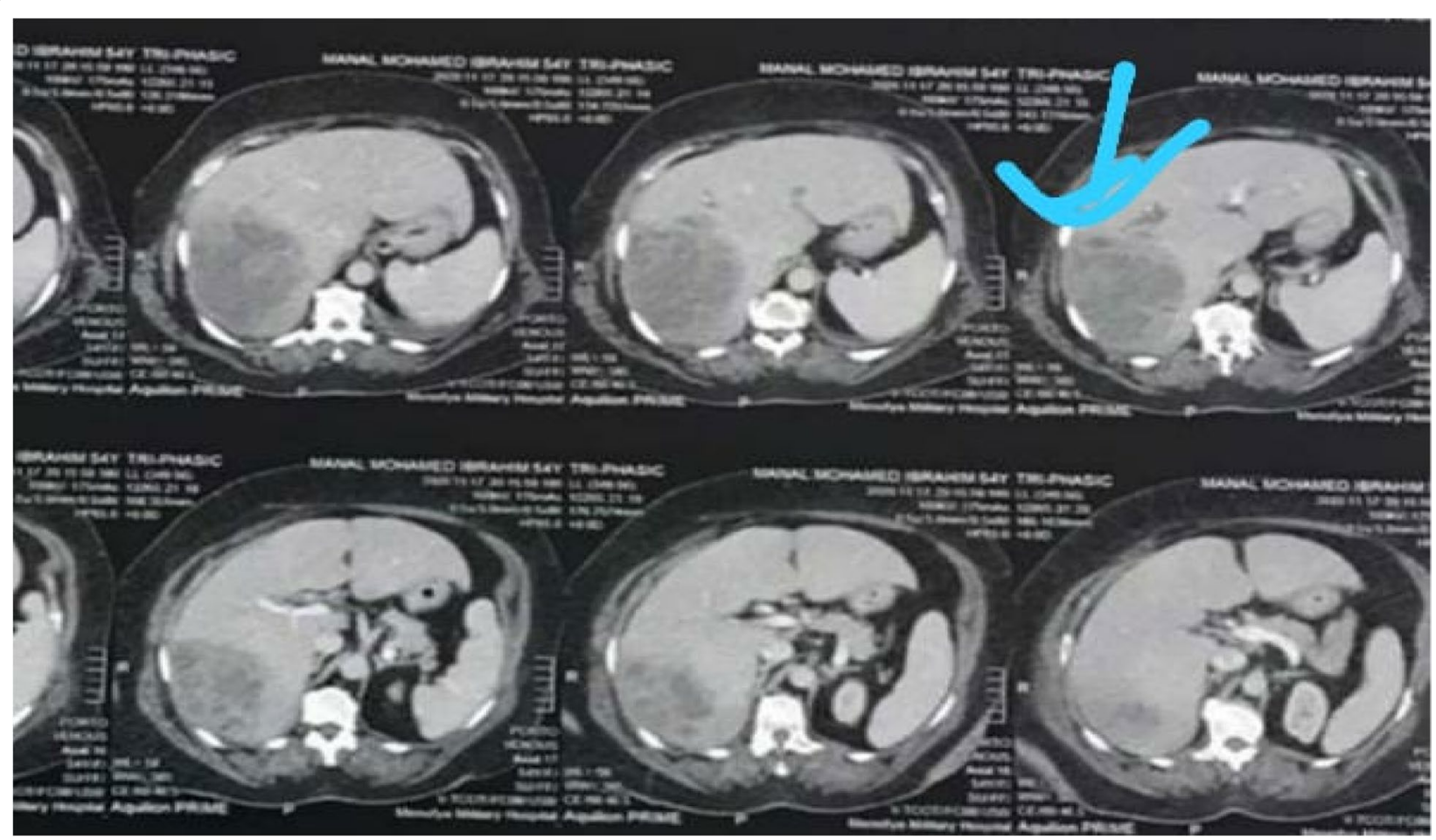

Fig. 2 A large right lobe liver abscess with a potential biliary linkage in a biliary-cut 


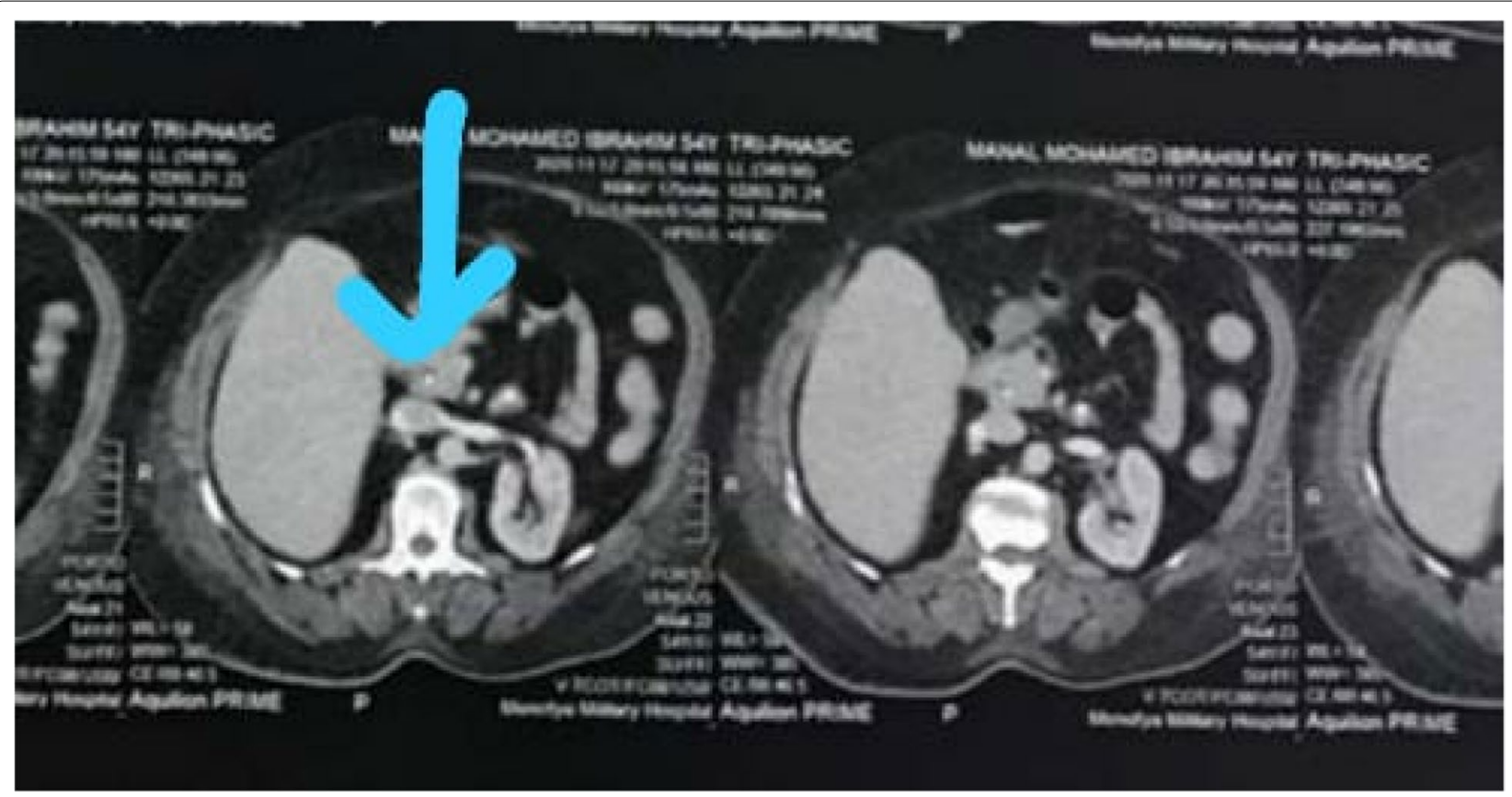

Fig. 3 A faint thin stent hardly seen (atypical surgical catheter) on CT images

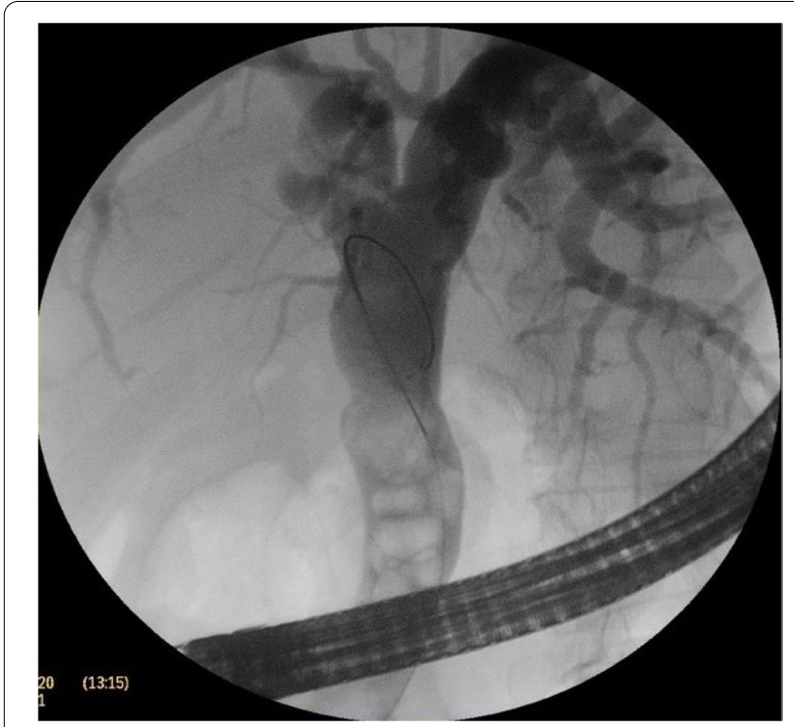

Fig. 4 A cholangiogram showing mildly dilated CBD studded with multiple stones

dilated central biliary radicals. Surprisingly, an old stent was hardly seen inside the dilated CBD, with mild dilatation of the intrahepatic biliary channels (Figs. 4, 5, and 6).

Papillotomy and papilloplasty were undertaken followed by stones' extraction by a balloon extractor. The procedure was ended by inserting 2 plastic stents (10 $\mathrm{cm} \times 10 \mathrm{f}$ ), and a flow of thick dark bile was inspected.

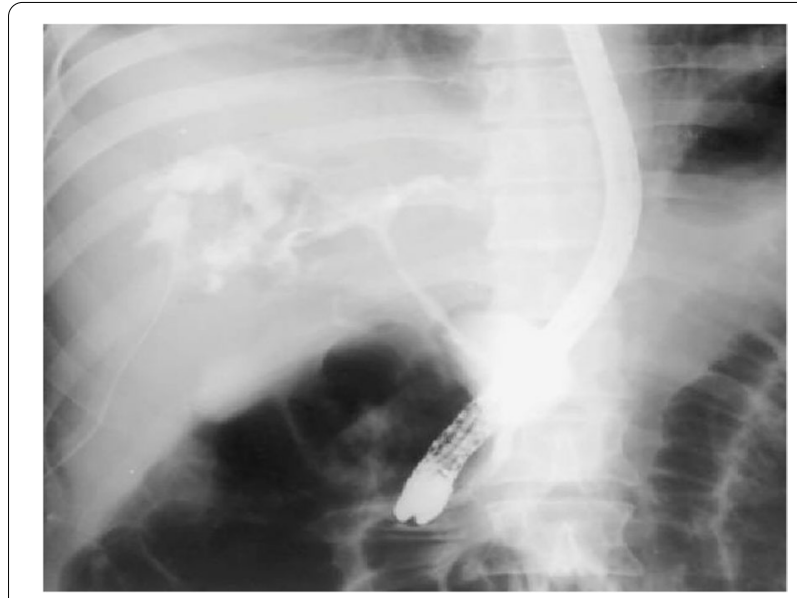

Fig. 5 Extravasation of the contrast into the abscess cavity proofing the linkage with the biliary tree

Finally, the patient fully recovered, and the pigtail was removed. Follow-up 2 weeks later revealed stable recovery.

\section{Discussion}

Choledocholithiasis is still considerably observed after cholecystectomy and stones can be either old or newly formed [5]. In the present case, the remote history of cholecystectomy signified the stones on the CBD as de novo choledocholithiasis. 


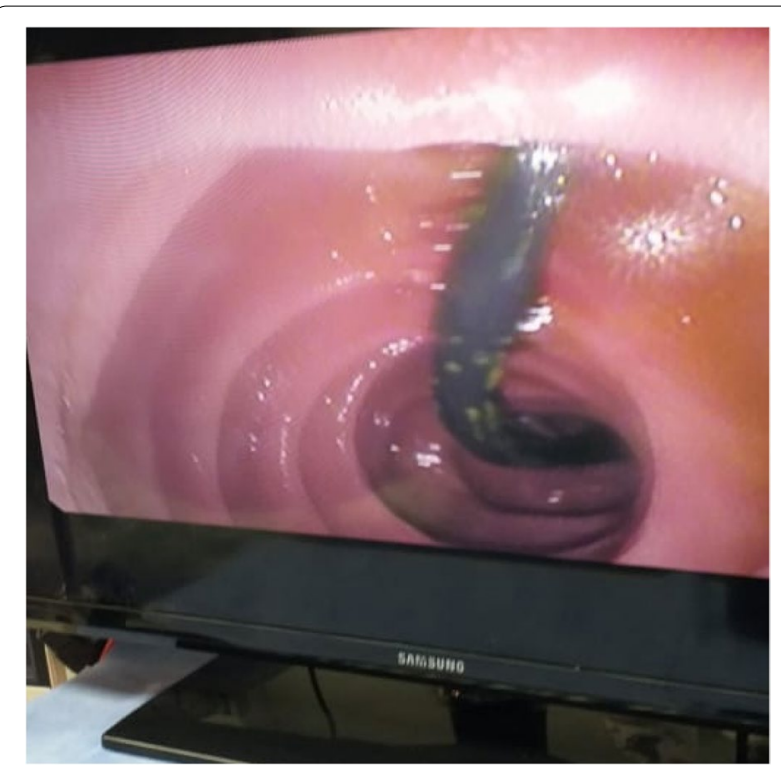

Fig. 6 The slipped surgical catheter

During cholecystectomy and in a case of retained CBD stones, the trans-papillary biliary stenting after CBD compression is considered as an attractive option to avoid T-tube-related complications [6]. Furthermore, it eases clearing the CBD from any calculi during a planned ERCP to retrieve the intraoperatively applied trans-papillary stent [7]. In the present patient, it is clear that the surgically placed stent had been forgotten for 20 years.

Neglected biliary plastic stents may act as a core of matrix for lithogenesis triggered by partial obstruction and slowing of the bile flow [8]. In that milieu, the longretained biliary stent can foster bacterial proliferation and release of the enzyme beta-glucuronidase, and subsequent precipitation of calcium bilirubinate that then aggregated into stones by an anionic glycoprotein [9].

The initial non-resolution of the abscess despite the pigtail drainage and culture-sensitivity-guided antibiotics then the cholangiographic picture and rapid resolution after adequate biliary drainage, all prove a communication of the abscess with the intrahepatic biliary system.

The mechanism that would explain the post-COVID liver abscess formation in this patient is apparently hard to reach. One speculation could be the immune evasion which perpetually was described as a sequel of SARS-COV2 infection. The virus-mediated immunosuppression enables opportunistic bacteria to colonize vulnerable tissues in the affected patients [10]. The forgotten stent, the partially obstructed biliary system, the new calculi, and the surrounding liver tissue all were providing such vulnerability to post COVID-19 bacterial infection.
In viral pandemics, bacteremia particularly with Staphylococcus aureus has been long documented and accused of the associated morbidity and mortality [11]. Severity of the disease and mortality in Spanish flu (1918-1919) and the H1N1 influenza pandemic (2009-2010) are largely attributed to secondary bacteremia [12]. In the recently published reports, staph aureus bacteremia has been documented in patients infected with SARS-CoV-2 [13]. Two reports from New York City have documented bacteremia in patients who suffered from COVID-19. Sepulveda et al. reported that $1.6 \%$ of COVID-19 patients had bacteremia, with S. aureus accounting for $13 \%$ of these bacteremias [14]. Nori et al. reported that $1.9 \%$ of COVID-19 patients can develop bacteremias [2].

In recent years, biliary tract disease is the most common source of pyogenic liver abscess [15]. In such a condition, abscesses are usually multiple; however, solitary abscess can occur because of surgical manipulation or indwelling biliary stents [16].

Thus, another speculation in the presented case is that COVID-19 pneumonia-associated systemic bacteremia along with hematogenous dissemination can be the background pathology behind bacterial cholangitis and abscess formation.

E. coli is the prevalent liver abscesses pathogen and had been incriminated in triggering right lobe solitary abscesses $[17,18]$.

COVID-19 had been convicted in many liver derangements starting from just elevated liver enzymes up to acute fulminant liver failure supporting the hepatic injurious nature of the virus $[19,20]$. A condition might be the clue of this case, as the ongoing COVID-19 hepatic injury paved the way to be the bed for $E$. coli proliferation and invasion in an immunocompromised patient with an overlooked biliary stent.

The presenting case is exceptional for the asymptomatic de novo choledocholithiasis projecting over the 20-year forgotten surgically applied trans-papillary stent. Also, the post-COVID cholangitic abscess was overheading a quiescent biliary disease.

\section{Conclusion}

In this case, the unique sequel of COVID-19 appraises a new aspect for that threatening virus. More importantly, it necessitates careful evaluation of COVID-19 affected patients, and a full eye follow-up after recovery.

\section{Abbreviations \\ CBD: Common bile duct; ERCP: Endoscopic retrograde cholangiopancreatography.}

\section{Acknowledgements}

All authors are indebted to Professor/ Omkolsoum Alhaddad for her great efforts in fulfilling this work 


\section{Authors' contributions}

EO analyzed and interpreted the patient data and was a major contributor in writing the manuscript. EM helped in writing and revising the manuscript. EE performed the endoscopic intervention. EA helped in case analysis. ED helped in drug data analysis of the case. MT revised the rationalities of the case and contributed to the data interpretation, along with manuscript final revision. All authors read and approved the final manuscript.

\section{Funding}

No funding resources.

\section{Availability of data and materials}

All the data is available in the manuscript.

\section{Declarations}

\section{Ethics approval and consent to participate}

The case was written after the consent of the ethical committee of National Liver Institute Menoufia University.

\section{Consent for publication}

Written informed consent was obtained from the patient for publication of this case report and accompanying images.

\section{Competing interests}

The authors declare that they have no competing interests.

\section{Author details}

1 Department Of Hepatology and Gastroenterology, National Liver Institute, Menoufia University, Shebeen El-Kom 32511, Egypt. ${ }^{2}$ Department Of Clinical Pharmacy, National Liver Institute, Menoufia University, Shebeen El-Kom 32511, Egypt. ${ }^{3}$ Department Of Internal Medicine, Faculty of medicine, Ain Shams University, Cairo, Egypt.

Received: 20 July 2021 Accepted: 30 December 2021

Published online: 11 January 2022

\section{References}

1. Mackenzie JS, Smith DW (2020) COVID-19: a novel zoonotic disease caused by a coronavirus from China: what we know and what we don't [published online ahead of print, 2020 Mar 17]. Microbiol Aust. MA20013

2. Nori P, Cowman K, Chen V et al (2020) Bacterial and fungal coinfections in COVID-19 patients hospitalized during the New York City pandemic surge [published online ahead of print, 2020 Jul 24]. Infect Control Hosp Epidemiol::1-5

3. Shi SH, Zhai ZL, Zheng SS (2018) Pyogenic liver abscess of biliary origin: the existing problems and their strategies. Semin Liver Dis. 38(3):270-283

4. Mischnik A, Kern WV, Thimme R (2017) Pyogenic liver abscess: changes of organisms and consequences for diagnosis and therapy. Dtsch Med Wochenschr. 142(14):1067-1074

5. Chowbey P, Sharma A, Goswami A et al (2015) Residual gallbladder stones after cholecystectomy: a literature review. J Min Access Surg 11:223-230

6. Hassan AM, Mohamed AQ, Shawky AM (2017) Common bile duct exploration with trans-papillary stenting versus T-tube drainage for management of irretrievable common bile duct stones. Al-Azhar Assiut Med J 15:117-121

7. Dietrich A, Alvarez F, Resio N et al (2014) Laparoscopic management of common bile duct stones: trans-papillary stenting or external biliary drainage. JSLS. 18(4):e2014.00277

8. Odabasi M, Arslan C, Akbulut S et al (2014) Long-term effects of forgotten biliary stents: a case series and literature review. Int J Clin Exp Med. 7(8):2045-2052

9. Barai V, Hedawoo J, Changole S (2017) Forgotten CBD stent (102 months) with stone-stent complex: a case report. Int J Surg Case Rep. 30:162-164

10. Desforges M, Coupanec A, Dubeau PH et al (2019) Human coronaviruses and other respiratory viruses: underestimated opportunistic pathogens of the central nervous system? Viruses 12:14
11. Siddiqui AH, Koirala J. Methicillin resistant Staphylococcus aureus. [Updated 2020 Jul 19]. In: StatPearls [Internet]. Treasure Island (FL): StatPearls Publishing; 2020 Jan-. Available from: https://www.ncbi.nlm.nih. gov/books/NBK482221/.

12. Morens DM, Taubenberger JK, Harvey HA et al (2010) The 1918 influenza pandemic: lessons for 2009 and the future. Crit Care Med. 38(4 Suppl):e10-e20

13. Cusumano A, Dupper C, Yesha M et al (2020) Staphylococcus aureus bacteremia in patients infected with COVID-19: a case series, Open Forum. Infectious Diseases 7(11):ofaa518

14. Sepulveda J, Lars F, Westblade L et al (2020) Green bacteremia and blood culture utilization during COVID-19 surge in New York City. J Clin Microbiol 58(8):e00875-e00820

15. Sugiyama M, Atomi Y (2002) Pyogenic hepatic abscess with biliary communication. Am J Surg. 183(2):205-208

16. Engler S, Benz C, Martin WR et al (1997) Leberabszesse--Komplikationen nach Prothesen- und Stentokklusionen [Liver abscesses--complications after prosthesis and stent occlusions]. Ultraschall Med. 18(6):262-266

17. Chen SC, Yen CH, Lai KC et al (2005) Pyogenic liver abscesses with Escherichia coli: etiology, clinical course, outcome, and prognostic factors. Wien Klin Wochenschr. 117(23-24):809-815

18. Yoon JH, Kim YJ, Kim SI (2019) Prognosis of liver abscess with no identified organism. BMC Infect Dis 19:488

19. Jothimani D, Venugopal R, Abedin MF et al (2020) COVID-19 and the liver. J Hepatol. 73(5):1231-1240

20. Melquist S, Estepp K, Aleksandrovich Y et al (2020) COVID-19 presenting as fulminant hepatic failure: a case report. Medicine (Baltimore). 99(43):e22818

\section{Publisher's Note}

Springer Nature remains neutral with regard to jurisdictional claims in published maps and institutional affiliations.

\section{Submit your manuscript to a SpringerOpen ${ }^{\circ}$ journal and benefit from:}

- Convenient online submission

- Rigorous peer review

- Open access: articles freely available online

- High visibility within the field

- Retaining the copyright to your article

Submit your next manuscript at $\boldsymbol{\nabla}$ springeropen.com 